\title{
Collection and Identification of Pollen from Honey Bee Colonies
}

\author{
Ellen Topitzhofer ${ }^{1}$, Hannah Lucas ${ }^{1}$, Emily Carlson ${ }^{1}$, Priyadarshini Chakrabarti ${ }^{1}$, Ramesh Sagili ${ }^{1}$ \\ ${ }^{1}$ Department of Horticulture, Oregon State University
}

\section{Corresponding Author}

Ramesh Sagili

Ramesh.Sagili@oregonstate.edu

\section{Citation}

Topitzhofer, E., Lucas, H., Carlson, E., Chakrabarti, P., Sagili, R. Collection and Identification of Pollen from Honey Bee Colonies. J. Vis. Exp. (167), e62064, doi:10.3791/62064 (2021).

\section{Date Published}

January 19, 2021

\section{DOI}

$10.3791 / 62064$

URL

jove.com/video/62064

\section{Abstract}

Researchers often collect and analyze corbicular pollen from honey bees to identify the plant sources on which they forage for pollen or to estimate pesticide exposure of bees via pollen. Described herein is an effective pollen-trapping method for collecting corbicular pollen from honey bees returning to their hives. This collection method results in large quantities of corbicular pollen that can be used for research purposes. Honey bees collect pollen from many plant species, but typically visit one species during each collection trip. Therefore, each corbicular pollen pellet predominantly represents one plant species, and each pollen pellet can be described by color. This allows the sorting of samples of corbicular pollen by color to segregate plant sources. Researchers can further classify corbicular pollen by analyzing the morphology of acetolyzed pollen grains for taxonomic identification. These methods are commonly used in studies related to pollinators such as pollination efficiency, pollinator foraging dynamics, diet quality, and diversity. Detailed methodologies are presented for collecting corbicular pollen using pollen traps, sorting pollen by color, and acetolyzing pollen grains. Also presented are results pertaining to the frequency of pellet colors and taxa of corbicular pollen collected from honey bees in five different cropping systems.

\section{Introduction}

The western honey bee (Apis mellifera L.) is an important pollinator of many agricultural crops that depend on bee pollination ${ }^{1}$. For more than a decade, significant honey bee colony losses have been reported $2,3,4,5,6,7,8,9$. Several factors-including parasites and diseases, poor nutrition and pesticides-have been implicated in these colony declines ${ }^{10}$. Poor nutrition can be attributed to agricultural intensification and loss of foraging habitat ${ }^{11}$. It is imperative to understand the floral resources utilized by bees in different landscapes to improve bee nutrition and aid in bee conservation efforts. Pollen is the primary source of protein, lipids, vitamins, and minerals for bees and has been used in many agricultural and ecological studies to understand colony-level foraging preferences of honey bees, evaluate the impact of pollen 
trapping on honey bee colonies, and determine pesticide exposure to bees ${ }^{12,13,14}$.

Honey bees gather pollen from flowers, pack pollen into pellets on their corbicula - a tibial pollen basket on their hindleg - and return to the colony for storage. Corbicular pollen can be removed from foragers by capturing them at the hive entrance or on flowers, chilling them briefly to immobilize them, and then removing the pollen pellets from their hindlegs with forceps. The laborious process of handcollecting corbicular pollen from individually captured foragers is slow and inefficient if one requires a considerable quantity of pollen. A simpler and more efficient method of collecting large volumes of pollen is by trapping corbicular pollen pellets from honey bees at hive entrances. Pollen traps are designed to dislodge corbicular pollen from the legs of the returning pollen foragers as they enter the hive ${ }^{15}$. The foragers must squeeze through mesh holes that are sized to narrowly allow the passage of a honey bee worker body.

As the honey bee passes through one of these holes, the larger pollen pellets are scraped off her legs and fall into a collection tray ${ }^{16}$. Studies have shown that pollen trapping stimulates foragers to collect more pollen, thus increasing the pollination efficiency of the surrounding crops and vegetation $17,18,19,20$. Pollen collection methodologies can also be used to understand the forage utilized by honey bees in the landscape as the first step to determining the quantity, quality, and taxa of flowering plant species. Effective pollentrapping methodologies thus facilitate both pollination and honey bee nutrition research. A comparison of these pollen collection methods is illustrated in Table 1. Pollen foraging behavior will change based on the colony's need for stored pollen relative to its egg and larvae population levels ${ }^{21,22}$. As these changes include varying collection intensity, high variation in pollen quantity is often expected among colonies in the same location and among different locations of the same cropping system or landscape type 23,24 . Increasing the number of colonies and locations to trap pollen will help accommodate this variation.

Pollen traps vary in efficiency ${ }^{25,26}$. The size of pollen pellets collected by honey bees varies among plant species and can change based on the levels of pollen stores in the colony 27,28 . This poses the potential for smaller pollen pellets to be underrepresented and larger pellets to be overrepresented in samples collected via pollen traps. Adult bees vary in body size, which can also affect the representation of pollen collected in traps. There are also plant species that predominantly produce nectar that will be undetected if only assessing collected pollen in some landscapes. Trapping efficiency is also impacted by forager drift and disorientation, which is influenced by pollen trap type and the condition of the hive equipment. This problem can be mitigated by employing techniques specified in this paper. Investigators may consider additional research techniques, such as counting flower visitation by foragers, to supplement the results of colony-level foraging preferences. A useful method for assessing pollen diversity is sorting corbicular pollen by color. Although honey bees are generalist foragers, they also exhibit flower fidelity, where they collect pollen from the same plant species in the same location during any given collection trip. Based on this foraging behavior, it is assumed that any given corbicular pollen pellet is predominantly represented by a single plant species $27,29,30,31$. Hence, scientists can describe pollen diversity by sorting corbicular pollen by pellet color and reporting the total number of colors detected or the proportion of the total represented by each color group $12,32,33,34$. This can be accomplished by measuring the mass or pellet count of each color group. 
Measuring the pellet count of each color group is suggested if there are known or suspected systematic differences in the weight of pellets from different taxa. Systematic differences could be caused by pellet size or the quantity of nectar that foragers add to pollen when forming a pellet.

Color sorting is a time-efficient and simple process, but may not have acceptable accuracy for some pollination research studies because different plant taxa may have similar pollen pellet colors ${ }^{35,36}$. Additionally, there is a logistical limit to the number of distinct color groups pollen pellets can be separated into. Thus, the separation of each individual plant taxon pollen into its own distinct pellet color group may not always be possible in pollination studies. Morphological characterization of pollen grains via light microscopy often complements color separation of pellets by distinguishing the pollen of two or more taxa in pellets of the same color group. Although, it is common to find pollen grains of multiple taxa in a given pollen pellet color group, individual pollen pellets collected by a honey bee generally comprise one predominant taxon, possibly with other taxa in minor quantities. Thus, it is common to assume taxonomic fidelity in corbicular pollen pellets of honey bees. Pollen pellets from other pollinators that do not exhibit flower fidelity behavior, such as bumble bees, will often contain many plant species and may not possess a predominant taxon. In instances where quantitative estimates of taxa proportions in polyfloral pollen pellets are desired, microscopic methods that include acetolysis, are additionally required for proper analysis.

Assessing morphological characteristics of acetolyzed pollen grains is the most common method for taxonomic identification ${ }^{16}$. The acetolysis procedure removes the pollen grain's protoplasm to expose diagnostic characteristics that can be observed under light microscopy ${ }^{37,38}$. Using this method, researchers can report different taxa, frequency of taxa found in specific cropping systems, and predominant taxa of pellet colors ${ }^{33,36}$. Acetolysis is the best analytical technique for revealing pollen morphology ${ }^{28}$. However, some acetolyzed pollen grains, such as many Rosaceae types, cannot be identified to genus or species level through acetolysis and light microscopy alone. Researchers consider scanning electron microscopy or metabarcoding as alternative methods to achieve genus- or species-level identification. These alternative methods, however, only provide qualitative taxon identification and fail to estimate the proportions of different pollen grain taxa in polyfloral pollen pellets ${ }^{36,39}$. In addition, the expense and necessary expertise is considerably higher for these methods. A comparison of these identification methods is illustrated in Table 1.

\begin{tabular}{|c|c|c|c|c|}
\hline Methods & Time & Expense & Resolution & Expertise \\
\hline \multicolumn{5}{|l|}{ Pollen Collection } \\
\hline Pollen trapping & Low & Moderate & Variable & Moderate \\
\hline $\begin{array}{c}\text { Pollen forager } \\
\text { collection }\end{array}$ & High & Moderate & High & Low \\
\hline Pollen Identification & & & & \\
\hline
\end{tabular}




\begin{tabular}{|c|c|c|c|c|}
\hline $\begin{array}{c}\text { Visual (color } \\
\text { sorting only) }\end{array}$ & Moderate & Low & Low & Low \\
\hline Acetolysis & Moderate & Moderate & Moderate & High \\
\hline $\begin{array}{c}\text { Scanning electron } \\
\text { microscopy }\end{array}$ & High & High & High & High \\
\hline Metabarcoding & Variable & High & High & \\
\hline
\end{tabular}

Table 1: Comparison of different methods of pollen collection and identification based on time, expense, resolution, and expertise. Visual methods (color sorting only) report the total number of colors detected or the proportion of the total represented by each color group as a metric for determining pollen sources, but do not provide taxon identification.

The information available on trapping and sorting pollen and acetolyzing pollen grains is diverse and often spread across multiple sources, varying for researchers in different fields. This paper offers detailed insights into different types of pollen traps that can be used by both researchers and beekeepers to effectively collect large volumes of corbicular pollen. Also provided are protocols for preparing pollen samples - by acetolysis, staining, and slide mounting - for plant taxa identification. The methodologies detailed here are comprehensive and serve as a unique resource for identifying predominant plant species on which honey bees forage in a given landscape, particularly in cropping systems. Findings based on these methods from a previous study have been presented and document the diversity of pollen pellet colors and plant taxa from corbicular pollen collected by honey bees in five cropping systems ${ }^{14}$.

\section{Protocol}

\section{Collecting corbicular pollen from honey bee colonies using pollen traps}

1. Determine when to trap pollen from the desired apiary location.

NOTE: Ideal climatic conditions include full sun exposure, low wind speeds, low humidity, and no forecasted precipitation during the desired period for pollen collection.

2. Select optimal honey bee colonies for trapping pollen within the apiary location.

1. Assess colony strength by counting foragers returning to the colony entrance for $2 \mathrm{~min}$. Select colonies with the highest total number of returning foragers.

2. Select hives with woodenware that is in good condition, preferably without extra entrances and warped lids. Use colonies with fewer alternative entrances as they have increased likelihood of returning foragers reorienting to the trap entrance.

3. Select south-facing hive entrances whenever possible. If hives are palletized, install pollen traps on every colony facing the same direction on a given 
pallet to avoid the drift of foragers into neighboring hive entrances.

4. If desired, assess the brood nest of the colony by inspecting frames for the presence of larvae. Select colonies with relatively large amounts of larvae.

3. Install pollen traps on the selected honey bee colonies. NOTE: Installation will differ based on the type of pollen trap. Types include a) front-mount, b) bottom-mount, c) top-mount, or d) auger-hole entrance mount. See the discussion section for details.

1. For front-mount traps, attach the trap in front of the entrance with staples, screws, and tape, or connect the trap to bungee cords wrapped around the hive. For bottom-mount traps, place the trap underneath the lowest hive box, and fix the trap entrance near the original entrance. For auger-hole mount traps, attach the trap directly in front of an auger hole of a hive box using staples, screws, and tape. For topmount traps, place the trap above the uppermost hive box and below the lid.

4. Seal all other possible entrances into the colony by using non-adhesive and moldable material, such as latex or polyurethane foam, or \#8 hardware cloth $(2.7 \mathrm{~mm}$ aperture) for auger holes. Use adhesive tape for small cracks.

5. If using front-mount traps, place a barrier, such as a rubber mat, between the collection basket and grass to avoid moisture damage from dew.

6. Engage the trapping mechanism of the pollen trap 24 $\mathrm{h}$ after installation and before the day's foraging flight commences (late evening/early morning).
NOTE: This step is ideal, but not necessary. Engage pollen traps every other week if trapping pollen on the same colonies throughout a given period.

7. Collect corbicular pollen from the collection tray, place it into plastic bags or centrifuge tubes, and store in a cooler with ice.

1. To assess the diversity and abundance of pollen species, e.g., landscape-level nutrition studies, collect pollen in two or three $72 \mathrm{~h}$ intervals ${ }^{40}$.

2. For pesticide residue analysis, collect pollen in $\mathbf{2 4}$ $\mathrm{h}$ to $96 \mathrm{~h}$ intervals with a minimum of $3 \mathrm{~g}$ for processing $^{41}$.

8. Clean the pollen by removing bee parts and other hive debris.

NOTE: Use disposable gloves when handling pollen samples, and change the disposable gloves between samples. Use separate tools to remove debris from the pollen collected in each trap. Rinse and dry before using the tools for another batch of trapped pollen.

9. Store pollen at $-20{ }^{\circ} \mathrm{C}$ or below to maintain its compositional integrity if pollen is intended for pollen source identification, quantity assessment, or pesticide residue analyses ${ }^{41,42}$.

10. After removing the traps from the hives, sterilize all equipment in a $5 \%$ bleach solution, rinse, and dry the equipment before the next use.

\section{Pollen pellet color sorting for downstream pollen source identification and quantity assessment}

1. Ensure that there are at least $20 \mathrm{~g}$ of pollen sample to work with. Thoroughly mix the pollen sample in its bag or another suitably sized container to obtain a 
homogeneous mix of all pellets contained therein. To avoid unintentional bias in the next step, obscure the sample's color composition from view before removing a subsample from the sample bag.

2. Using a scooper or large spoon, scoop out $10 \mathrm{~g}$ of pollen as a representative subsample of the whole. Slowly pour pellets out of the scooper onto the balance until the display reads $10 \mathrm{~g}$. If the first scoop was not big enough, retrieve another scoop from the sample in the same way. NOTE: These specified weight requirements $(20 \mathrm{~g}$ and $10 \mathrm{~g})$ serve as examples only. Researchers should adjust the quantity of pollen used in each step as appropriate for specific needs.

3. Remove all bee parts and other debris from the $10 \mathrm{~g}$ subsample. Then, if necessary, add a little more pollen from the original sample to achieve a total weight of 10 $\mathrm{g}$ of the subsample.

4. Sort each pollen pellet from the $10 \mathrm{~g}$ subsample into a color group. Use both pollen color and texture to differentiate between color groups.

NOTE: Some variation within a group is expected, but using the Pantone color guide during sorting can increase consistency.

5. To ensure at least $0.25 \mathrm{~g}$ of each color group for downstream steps, place any pellets that are not plentiful enough to form a color group of at least $0.25 \mathrm{~g}$ into a miscellaneous group. Name each individual color group using the Pantone color guide. Label the miscellaneous group misc.

6. Weigh each color group on a separate weigh paper, and/or count the number of pellets in each color group. Record the color group names and weights or counts on a datasheet.
NOTE: Choosing whether to weigh or count the number of pellets in each color group depends on the researcher's metric of interest and project goals.

7. Create a microcentrifuge tube label for each color group using a solvent-resistant pen and adhesive paper tube labels. Include the current date, sample identifier, sample collection date, and color group number in the label. Apply the labels to clean, dry $2 \mathrm{~mL}$ microcentrifuge tubes.

8. Weigh out $0.25 \mathrm{~g} \mathrm{(} \pm 0.05 \mathrm{~g})$ of pollen pellets from each color group, and place this amount in the appropriately labeled microcentrifuge tube.

NOTE: If there is slight variation in color or texture in the pollen of a given color group, ensure that there is a representative sample of pellets within each tube. The reagent volumes and incubation and centrifugation times that follow are appropriate for $0.25 \mathrm{~g}$ of pollen. Therefore, use this quantity of pollen in the microcentrifuge tubes to be used in acetolysis. This protocol should provide ample, stained pollen for downstream plant source identification by light microscopy. If using a different quantity of pollen in acetolysis, the specifics of reagent volume and processing times should be adjusted accordingly.

9. Place the remaining pollen from each color group into individual plastic bags (one bag per color) labeled with the color group name. Store these bags with the other parts of the appropriate original sample in $-20^{\circ} \mathrm{C}$ storage.

10. Thoroughly mix the pollen in the tube with a clean wooden toothpick for 10 to $15 \mathrm{~s}$.

\section{Preparation for acetolysis}

1. Before beginning any part of acetolysis for the first time, contact the designated institution's environmental 
health and safety (EHS) department for instructions on how acetolysis-related reagents and waste should be handled.

2. Obtain stock solutions of the following reagents, and place them in the fume hood in accordance with EHS guidelines for chemical storage: 95\% ethanol; distilled water; glacial acetic acid, anhydrous; concentrated sulfuric acid; glycerin; and clear nail polish.

3. Prepare stock solutions of the following reagents, and place them in the fume hood in accordance with EHS guidelines for chemical storage: saturated sodium bicarbonate $(8 \% \mathrm{w} / \mathrm{v}$ solution in distilled water); and safranin $\mathrm{O}(1 \% \mathrm{w} / \mathrm{v}$ solution in $50 \%$ ethanol).

\section{Acetolysis}

1. Perform the pre-acetolysis procedure of glacial acetic acid wash. Carry out the following steps within the fume hood with lab coat, eye protection, and nitrile gloves.

1. Turn a heat block on to $80^{\circ} \mathrm{C}$.

NOTE: Ensure that a squeeze bottle of saturated sodium bicarbonate is easily accessible. This can be used to neutralize acid spills in the fume hood if they occur.

2. Label one glass beaker for acid waste, one for ethanol waste, and one for acetolysis mixture.

3. Using previously prepared stock solutions, create working aliquots of the following reagents in labeled, appropriately sized glass beakers: $\sim 23.0 \mathrm{~mL}$ of glacial acetic acid; $\sim 33.0 \mathrm{~mL}$ of distilled water; $\sim 23.0$ $\mathrm{mL}$ of $95 \%$ ethanol; $\sim 25.0 \mathrm{~mL}$ of sodium bicarbonate (for acid-contaminated solid waste).
NOTE: These are the volumes required to complete the following acetolysis procedures on a total of 10 color group samples (10 microcentrifuge tubes).

4. Slowly add $500 \mu \mathrm{L}$ of glacial acetic acid to each microcentrifuge tube containing $0.25 \mathrm{~g}$ of color group pollen. While visually inspecting the tube, stir the pollen with a clean toothpick for $10-15 \mathrm{~s}$, and ensure that the contents of the tube are thoroughly mixed. Place the used toothpick in the sodium bicarbonate waste beaker after use; repeat this process for each tube.

NOTE: Use a clean, new toothpick for each tube. Ensure that each tube's lid is tightly closed.

5. Centrifuge the samples for $3 \mathrm{~min}$ at $1,100 \times \mathrm{g}$. Decant the supernatant from the tubes into the acid waste beaker. Then, softly and briefly touch the open mouth of the tube with a clean paper towel to remove residual glacial acetic acid around the rim of the tube.

NOTE: Be careful not to lose the pollen pellet when decanting supernatants.

2. Perform the acetolysis procedure.

NOTE: Carry out the following steps within the fume hood with lab coat, eye protection, and butyl vinyl gloves.

1. Prepare the acetolysis mixture (9:1 glacial acetic acid:sulfuric acid) by first adding $10.8 \mathrm{~mL}$ of glacial acetic acid (from the working aliquot) to the beaker labeled acetolysis mixture. Then, using a $1000 \mu \mathrm{L}$ pipette fitted with $1250 \mu \mathrm{L}$ filtered pipette tips, slowly add $1200 \mu \mathrm{L}(1.2 \mathrm{~mL})$ of concentrated sulfuric acid from the stock solution to the acetolysis mixture beaker containing glacial 
acetic acid. Discard the used pipette tip into the beaker of sodium bicarbonate.

NOTE: The acetolysis mixture beaker may become warm to the touch, and the mixture may turn yellow. There are two possibilities that cause the mixture to turn a dark color: (a) the reagents may be past their expiration dates, or (b) too much sulfuric acid may have been added. In any case, if the mixture turns dark, discard it in the acid waste beaker, and prepare a fresh acetolysis mixture.

2. Gently stir the acetolysis mixture with a glass rod or wooden stir stick to ensure it is homogenized. Place the used rod/stick in the beaker of sodium bicarbonate.

3. Using a $1000 \mu \mathrm{L}$ pipette with $1250 \mu \mathrm{L}$ filtered pipette tips, slowly add $1000 \mu \mathrm{L}$ of acetolysis mixture from the beaker to each tube. While visually inspecting the tube, stir with a clean toothpick for $10-15 \mathrm{~s}$, and ensure that the contents of the tube are thoroughly mixed. Place the used toothpick in the sodium bicarbonate waste beaker after use.

NOTE: Use a clean, new toothpick for each sample.

4. Place the samples on the preheated $\left(80^{\circ} \mathrm{C}\right)$ heat block. Incubate the tubes for $5 \mathrm{~min}$, stirring each tube thoroughly with a clean toothpick halfway through incubation. Place each used toothpick in the beaker of sodium bicarbonate after use.

NOTE: Do not leave toothpicks in the samples; the acid will dissolve them.

3. Perform the post-acetolysis glacial acetic acid wash procedure.

NOTE: Carry out the following steps in the fume hood with lab coat, eye protection, and butyl vinyl gloves.
1. Slowly add $500 \mu \mathrm{L}$ of glacial acetic acid to each tube. While visually inspecting the tube, stir with a clean toothpick for 10-15 s, and ensure that the contents of the tube are thoroughly mixed. Place the used toothpick in the beaker of sodium bicarbonate after use.

NOTE: Use a clean, new toothpick for each sample. Ensure that each tube's lid is tightly closed.

2. Centrifuge the samples for $3 \mathrm{~min}$ at $1,100 \times \mathrm{g}$. Decant the supernatant from each tube into the acid waste beaker. Then, softly and briefly touch the open mouth of the tube with a clean paper towel to remove residual acid around the rim of the tube.

3. Thoroughly rinse the butyl vinyl gloves under running water for at least $30 \mathrm{~s}$, remove them, and set them to dry.

NOTE: Follow the manufacturer's guidelines on reuse of butyl vinyl gloves.

4. Perform three water rinses for each sample. Carry out the following steps within the fume hood with lab coat, eye protection, and nitrile gloves.

1. Add $1000 \mu \mathrm{L}$ of distilled water from the distilled water beaker to each tube. While visually inspecting the tube, stir with a clean toothpick for $10-15 \mathrm{~s}$, and ensure that the contents of the tube are thoroughly mixed. Place the toothpick in the sodium bicarbonate waste beaker after use.

NOTE: Use a clean, new toothpick for each sample. Ensure that each tube's lid is tightly closed.

2. Centrifuge the samples for $3 \mathrm{~min}$ at $1,100 \times \mathrm{g}$. Decant the supernatant from the tubes into the beaker of sodium bicarbonate. Then, softly touch the 
open mouth of the tube with a clean paper towel to remove residual water around the rim of the tube.

3. Repeat steps 4.4.1-4.4.2 two additional times for a total of three water rinses.

5. Perform the ethanol rinse for each sample.

NOTE: Carry out the following steps within the fume hood with lab coat, eye protection, and nitrile gloves.

1. Using a $1000 \mu \mathrm{L}$ pipette with $1250 \mu \mathrm{L}$ filtered pipette tips, add $1000 \mu \mathrm{L}$ of $95 \%$ ethanol from the ethanol beaker to each tube. Discard the pipette tip into nonhazardous waste. While visually inspecting the tube, stir with a clean toothpick for $10-15 \mathrm{~s}$, and ensure that the contents of the tube are thoroughly mixed.

NOTE: Place the toothpick in the sodium bicarbonate waste beaker after use. Use a clean, new toothpick for each sample. Ensure that each tube's lid is tightly closed.

2. Centrifuge the samples for $3 \mathrm{~min}$ at $1,100 \times \mathrm{g}$. Decant the supernatant from the tubes into the ethanol waste beaker, and softly touch the open mouth of the tube with a clean paper towel to remove residual ethanol from the tube.

6. Wear lab coat, eye protection, and nitrile gloves to stain samples. Mix the Safranin O stain stock solution using gentle inversion.

1. Using a disposable, plastic transfer pipette, add 5-10 drops of Safranin O stain to each tube. While visually inspecting the tube, stir with a clean toothpick for $10-15 s$, and ensure that the contents of the tube are thoroughly mixed. Leave the toothpick in the tube.

2. Using a $1000 \mu \mathrm{L}$ pipette with $1250 \mu \mathrm{L}$ filtered pipette tips, add $1000 \mu \mathrm{L}$ of $95 \%$ ethanol from the ethanol beaker to each tube. Discard the pipette tip into non- hazardous waste. While visually inspecting the tube, stir with the toothpick for $10-15 \mathrm{~s}$, and ensure that the contents of the tube are thoroughly mixed. Place the used toothpick in the non-hazardous waste after use.

3. Ensure that each tube's lid is tightly closed. Centrifuge for $3 \mathrm{~min}$ at $1,100 \times g$. Decant the supernatant into the ethanol waste beaker.

NOTE: Do not touch the mouth of the tube with a paper towel this time.

4. Add 10-15 drops of glycerin to each tube using a plastic disposable transfer pipette. While visually inspecting the tube, stir the contents of the tube with a clean toothpick for $10-15 \mathrm{~s}$, and ensure that the contents of the tube are thoroughly mixed.

NOTE: Place the used toothpick in the nonhazardous waste after use. Use a clean, new toothpick for each sample. Ensure that all tube labels are legible.

7. Leave the tubes open in the fume hood to evaporate the ethanol for at least $2 \mathrm{~h}$ at ambient room temperature. Check the samples for ethanol odor: if it is detectable, the samples are not ready and should be left to dry until the ethanol odor dissipates.

8. Clean all materials, and dispose of waste. Switch off both the centrifuge and heat block. Dispose of all solid and liquid waste in accordance with the designated institution's environmental health and safety guidelines.

9. Prepare microscope slides for pollen identification; label them legibly. Label a clean glass microscope slide appropriately for each color group/sample that will be mounted. While visually inspecting the tube, stir the 
sample with a clean toothpick for $10-15 \mathrm{~s}$, and ensure that the contents of the tube are thoroughly mixed.

NOTE: Slide preparation can be done at the lab bench. Discard the toothpick in nonhazardous waste. Use a clean, new toothpick for each sample.

1. Using a clean disposable plastic transfer pipette, remove 1 drop of pollen residue from a tube, and place it in the center of its labeled microscope slide. Allow the drop to spread slightly. Place a clean coverslip over the drop on the slide.

2. After the slide has dried, seal the coverslip to the slide with clear nail polish. Place a small drop of polish on each corner of the coverslip, and paint a border of polish around the perimeter of the coverslip where it meets the slide. Allow the nail polish to dry completely, and paint a second coat of polish around the perimeter of the coverslip.

\section{Representative Results}

A previous study reported the assessment of the diversity of pollen collected by honey bees in the following agricultural crops: almond, cherry, highbush blueberry, hybrid carrot, and meadowfoam ${ }^{14}$. Using the described methods, corbicular pollen was collected, sorted by color, and the plant sources of each pellet color group identified to assess pollen diversity. Bottom-mount pollen traps were installed on colonies in multiple sites for each crop (Figure 1A). The quantity of pollen collected from each site was enough to fulfill sample weight requirements of the color sorting and acetolysis analysis methods. Every pollen collection sample had multiple distinguishable color groups (Figure 2 and Figure 3). In some samples, pollen color groups contained as few as 4-5 pellets; however, most groups had significantly more than that and thus served as their own labeled color group for acetolysis (Figure 4 and Figure 5). After acetolysis (Figure 6), bright-field light microscopy was used to effectively identify each color group to its lowest possible taxonomic rank by confirming the morphological characteristics with those of voucher specimens collected from the area surrounding each study site (Figure 7).
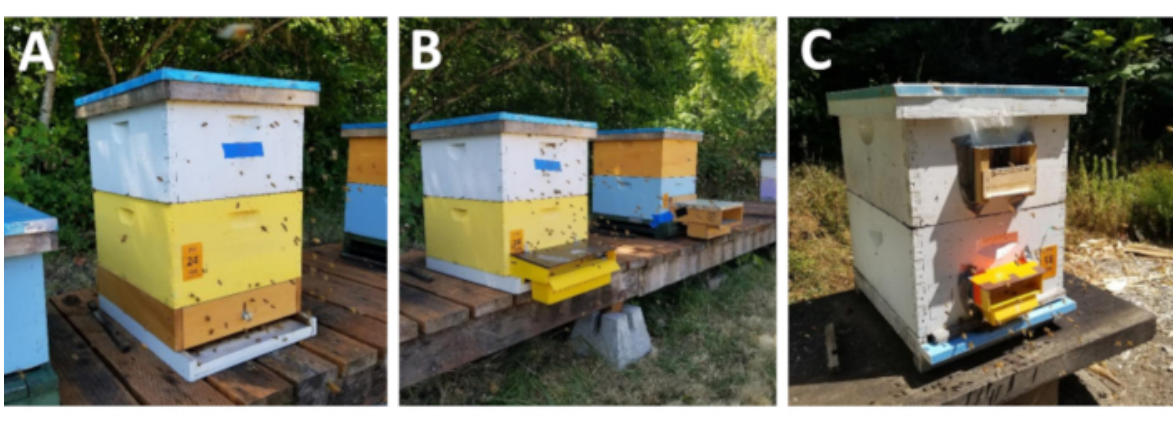

Figure 1: Pollen traps installed on a honey bee colony to collect corbicular pollen. (A) Bottom-mount traps placed above the hive bottom board and directly above the lowest hive box. Other pollen trap styles include (B) front-mount and (C) auger-hole entrance mount traps. Please click here to view a larger version of this figure. 


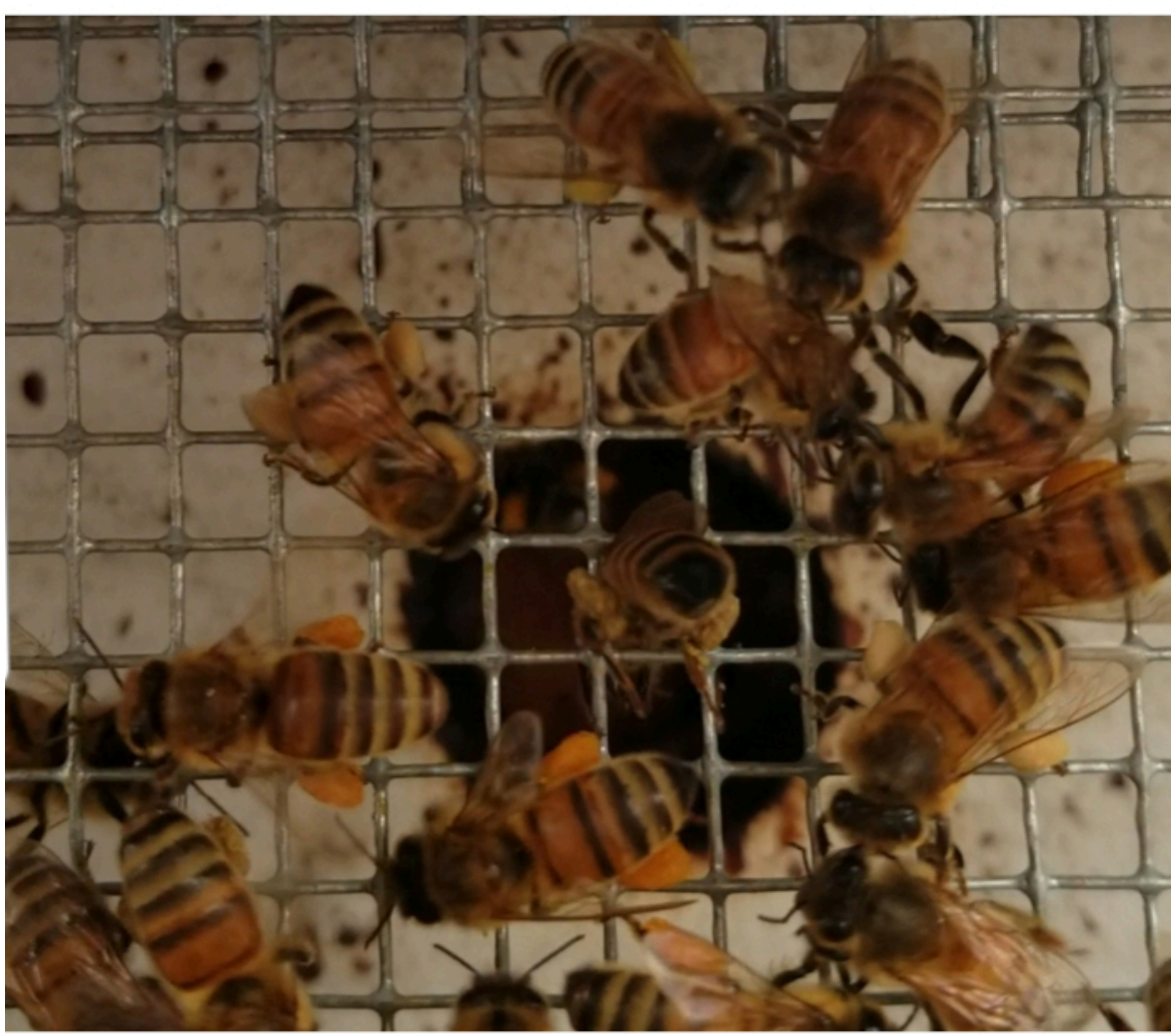

Figure 2: Trapping mechanism and collection tray of pollen trap. Returning pollen foragers must squeeze through the mesh trapping mechanism before reaching their hive. Please click here to view a larger version of this figure. 


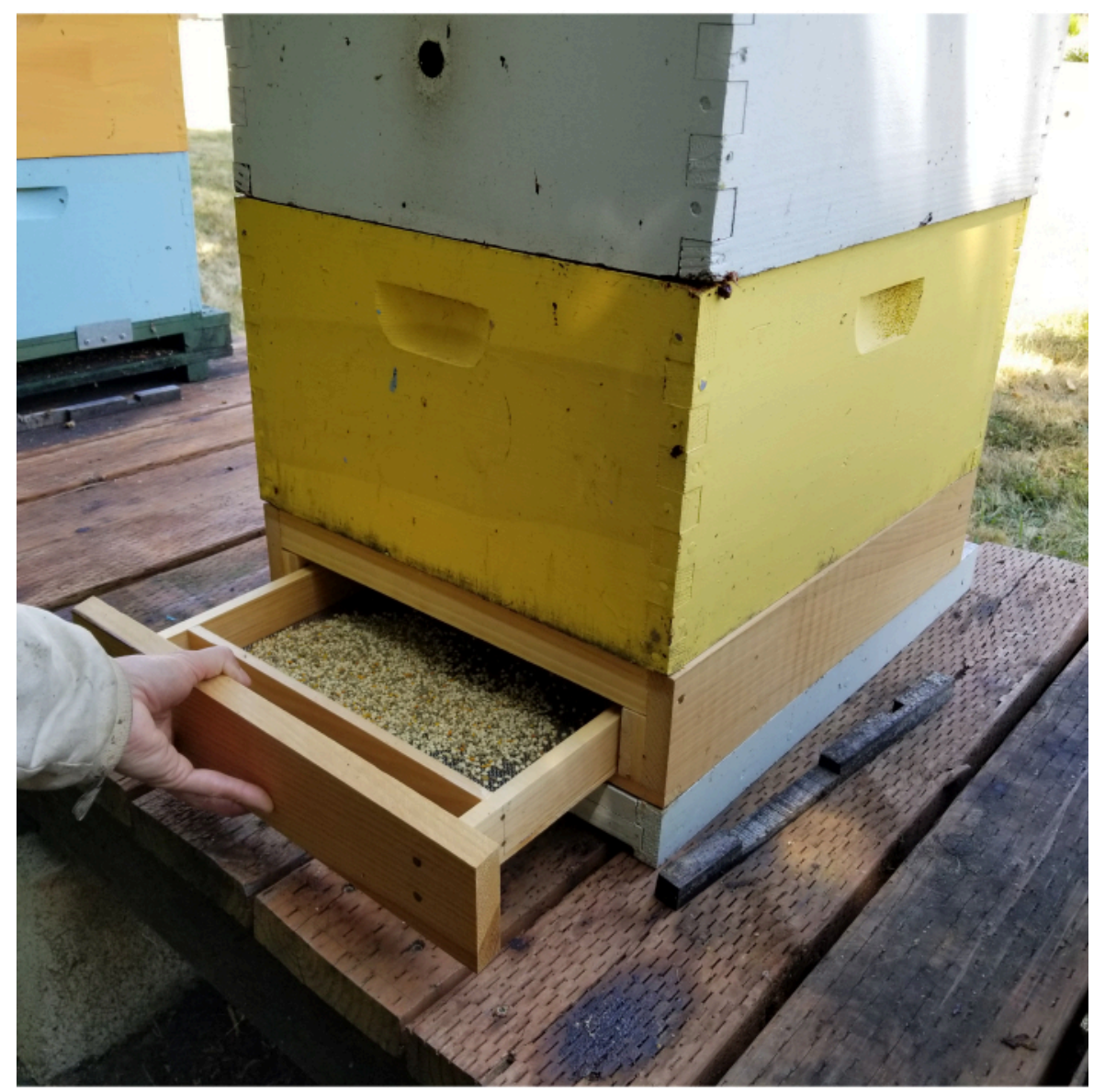

Figure 3: Collection tray of pollen trap. Corbicular pollen is scraped off the legs of returning pollen foragers by the pollen trap and falls into the collection tray. Please click here to view a larger version of this figure. 


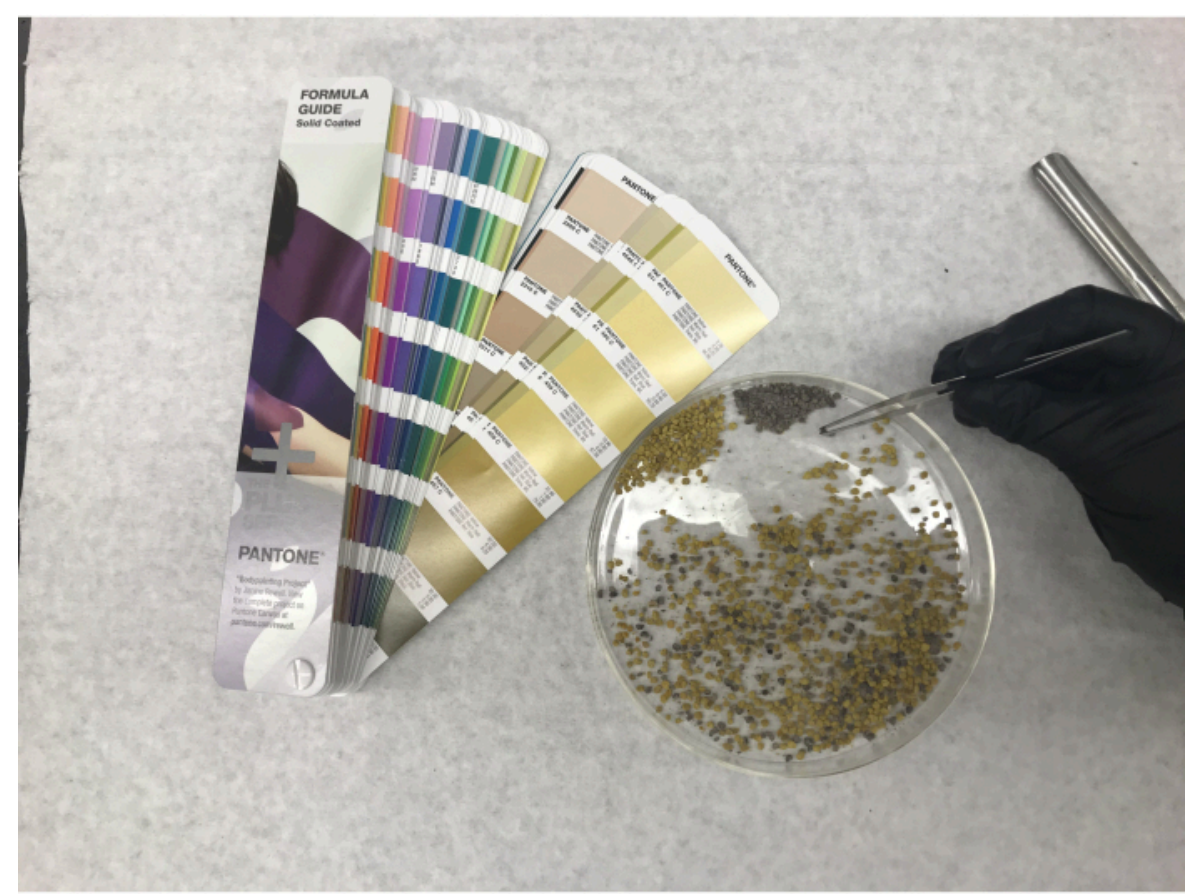

Figure 4: Sorting a sample of corbicular pollen into color groups. Corbicular pollen can be dried and weighed after it is sorted into color groups to report proportions of different color pellets collected. Please click here to view a larger version of this figure. 

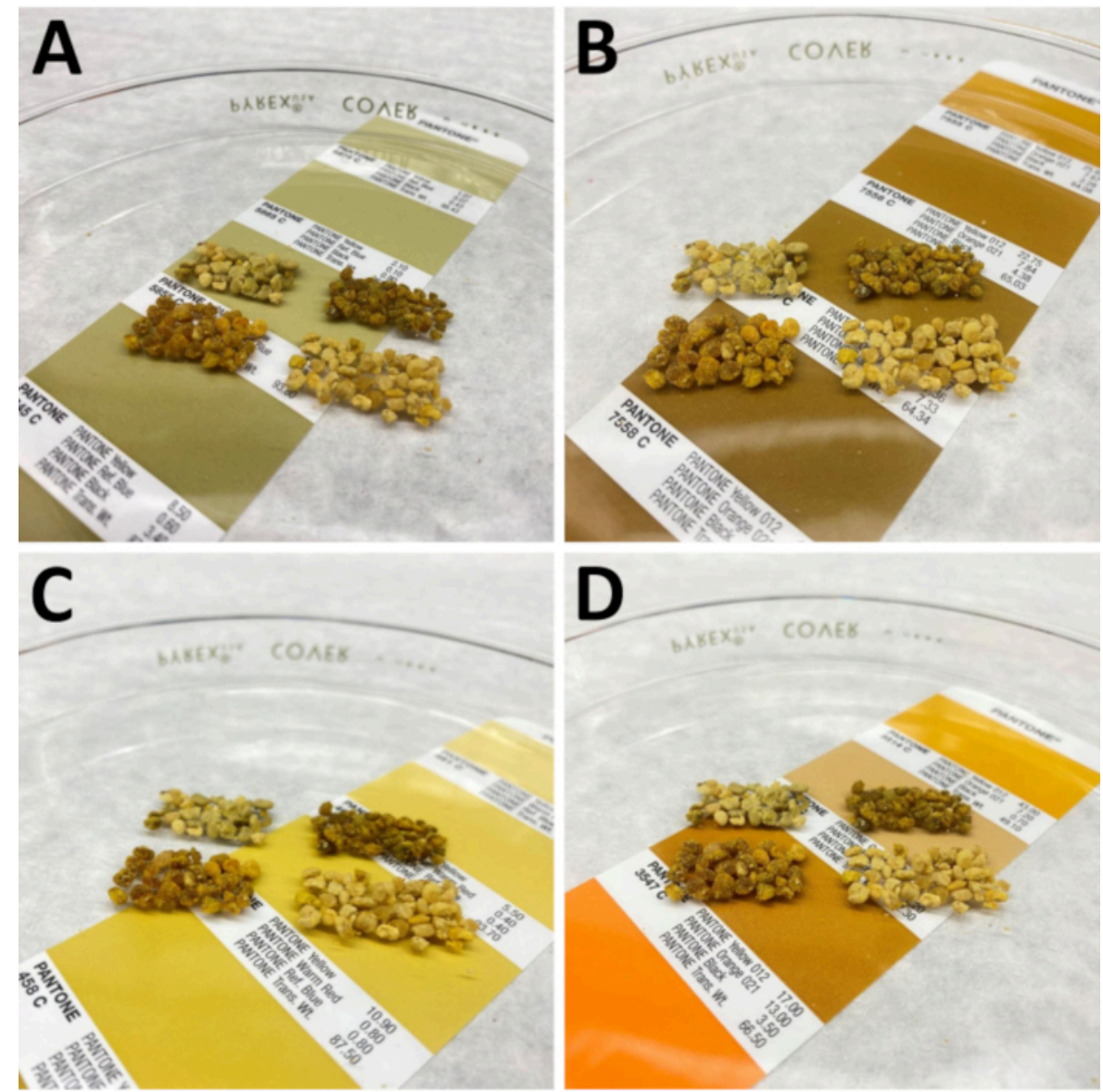

Figure 5: Four groups of pollen pellets sorted by color using the Pantone color guide. The color groups are labeled as (A) gray, Pantone 5855C, (B) brown, Pantone 7557C, (C) yellow, Pantone 458C, and (D) light brown, Pantone 3547C. Please click here to view a larger version of this figure. 


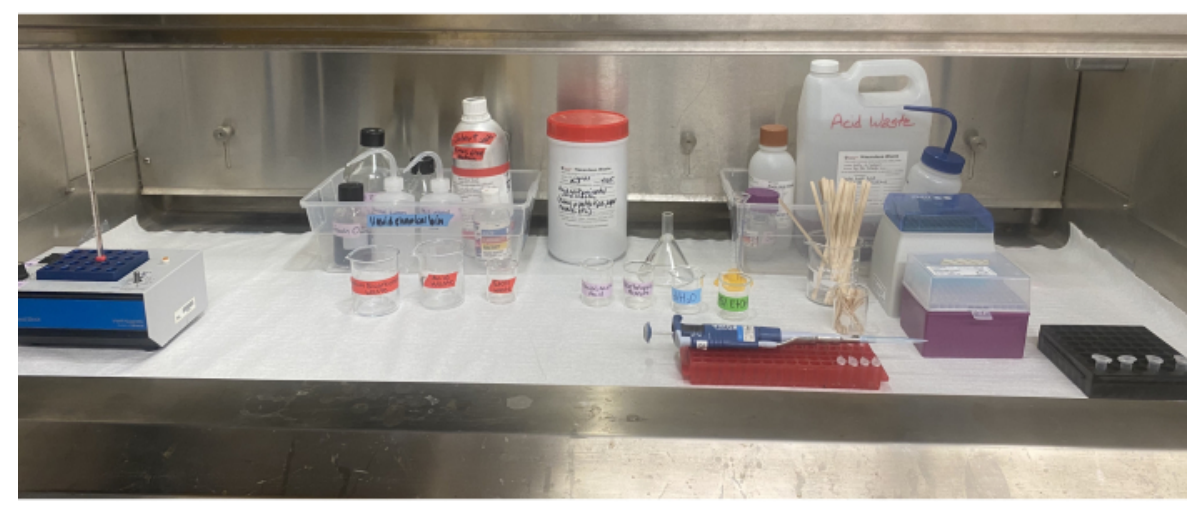

Figure 6: Acetolysis equipment setup inside the fume hood. The heat block, reagents, solvent waste and acid waste containers, labeled beakers, pipette, pipette tips, stir sticks, and microcentrifuge tubes situated inside the fume hood. Please click here to view a larger version of this figure.

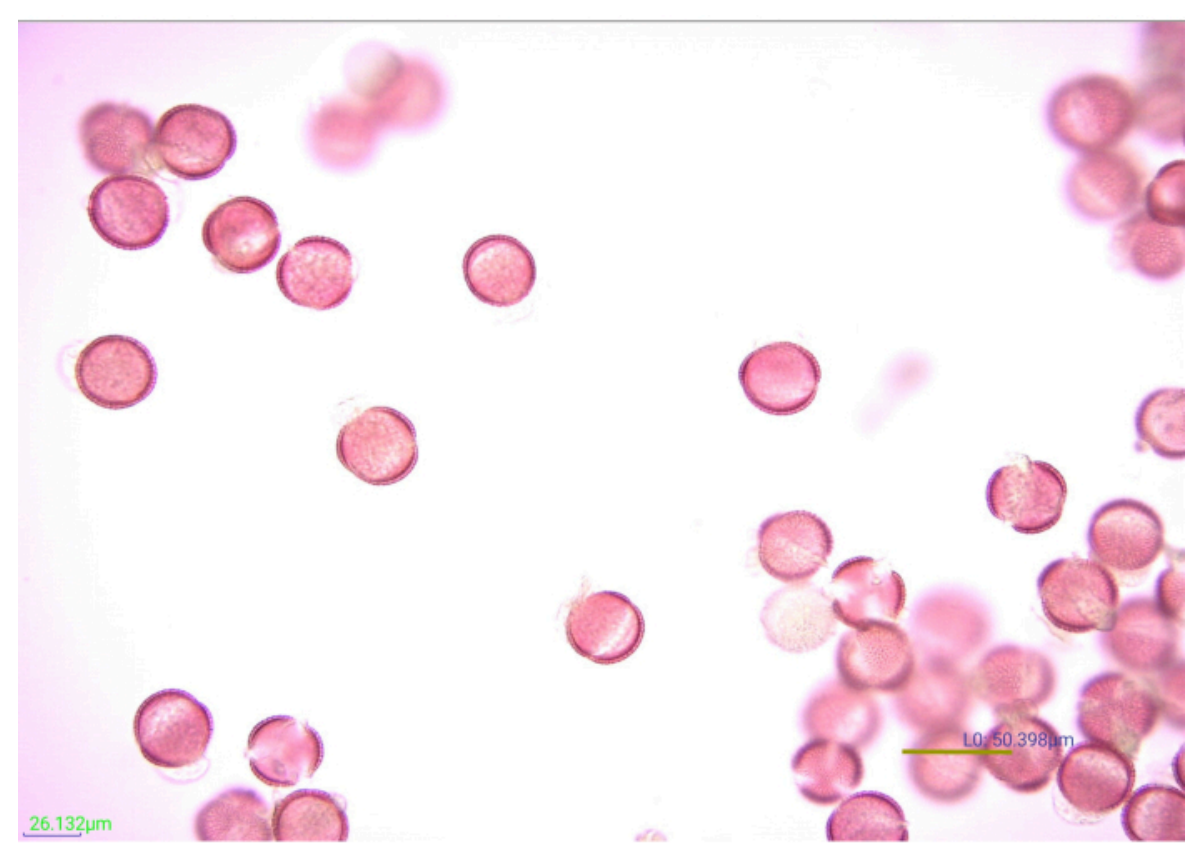

Figure 7: Micrograph of stained, acetolyzed pollen grains. Many facets of acetolyzed mustard (Brassicaceae) pollen grains at 40x magnification. Scale bar $=50.398 \mu \mathrm{m}$. Please click here to view a larger version of this figure.

The pollen collected from almond crop locations had relatively lower pollen diversity than pollen collected from other crops, with an average of $3.0 \pm 0.5$ pellet colors and $3.2 \pm 1.2$ plant taxa per site (Table 2) ${ }^{14}$. The remaining four cropping systems had higher pollen diversity levels with an average of $6.0 \pm 2.0$ pellet colors and $8.0 \pm 1.5$ plant taxa per site in 
cherry, $8.8 \pm 1.4$ pellet colors and $13.5 \pm 2.0$ plant taxa per site in highbush blueberry, $7.0 \pm 1.0$ pellet colors and $11.0 \pm$
0.0 plant taxa per site in hybrid carrot, and $10.0 \pm 0.0$ pellet colors and $13.0 \pm 1.5$ plant taxa per site in meadowfoam ${ }^{14}$.

\begin{tabular}{|c|c|c|c|c|c|}
\hline Crop & $\begin{array}{c}\text { Mean number } \\
\text { of pollen pellet } \\
\text { colors/site (SE) }\end{array}$ & $\begin{array}{c}\text { Mean number } \\
\text { of plant taxa/ } \\
\text { site (SE) }\end{array}$ & \multicolumn{3}{|c|}{ Total taxa identified } \\
\hline & & & Family & Genus & Species \\
\hline Almond & $3.0(0.5)$ & $3.2(1.2)$ & 4 & 3 & 4 \\
\hline Blueberry & $8.8(1.4)$ & $13.5(2.0)$ & 5 & 10 & 6 \\
\hline Carrot & $7.0(1.0)$ & $11.0(0.0)$ & 3 & 5 & 5 \\
\hline Cherry & $6.0(2.0)$ & $8.0(1.5)$ & 4 & 4 & 14 \\
\hline Meadowfoam & $10.0(0.0)$ & $13.0(1.5)$ & 5 & & 6 \\
\hline
\end{tabular}

Table 2: Diversity of corbicular pollen collected from honey bees in five cropping systems. Diversity metrics include mean number of pellet colors $( \pm S E)$, mean number of plant taxa $( \pm \mathrm{SE})$, and total taxa identified. This table has been modified from ${ }^{14}$. Abbreviation: $\mathrm{SE}=$ standard error.

\section{Discussion}

Different pollen trap styles have their own advantages and consequences. The benefits and limitations of four commonly used trap styles, (1) front-mount, (2) bottom-mount, (3) augerhole, and (4) top-mount pollen traps are discussed below. Front-mount traps are the most versatile style (Figure 1B). Installation is fast and easy; it can be done without lifting hive boxes, and these traps can fit on any Langstroth style of hive equipment. As the collection tray sits in front of the colony, it collects minimal debris from the colony. However, the collection tray is also more exposed to external elementsmoisture from field irrigation, rainy or humid weather, or dew can come into contact with the pollen through the collection tray, potentially rendering the pollen unusable if the pellets become too saturated to separate. The risk of pollen saturation can be reduced by avoiding trapping during forecasted events of rain or high humidity. Placing a rubber mat under the trap and extra covering material (e.g., roofing felt) on top of the pollen trap can also shield the collection tray from weather.

Bottom-mount traps were used to collect pollen for the data in this paper (Figure 1A). They are not as convenient to install because they must be placed underneath the brood nest of the colony. Installation is time-consuming and results in a high volume of debris falling into the trap from the colony, such as bee parts and small bits of wax. The floor of the collection tray for most manufactured bottom-mount traps is made of fine mesh, which allows proper ventilation to protect the collected pollen from moisture. Auger-hole pollen traps help minimize disorientation of foragers if they primarily use auger holes as hive entrances instead of the entrance made by the bottom board of the hive (Figure 1C). As the collection tray for auger- 
hole pollen traps is very small, it must be emptied frequently to avoid overflowing of the collection tray. Given its upper placement on a hive, the top-mount pollen trap is the easiest trap style to install and remove, and the collected pollen sample is free of hive debris. However, this trap style is extrasensitive to damaged hive equipment as the collection tray would be exposed to moisture if the lid, inner cover, and upper hive box are not properly sealed together.

The protocols described herein call for selecting colonies with large adult and larval populations (step 1.2). This selection method is intended to produce very large amounts of trapped pollen from these colonies. Colonies with substantial foraging populations may experience heavy congestion at the entrance upon trap installation. Selecting a large hive entrance will alleviate congestion. Large foraging populations may also collect very large quantities of pollen that can exceed the bounds of the collection tray. Use voluminous collection trays, as seen with most bottom- or top-mount trap styles, and empty trays frequently to accommodate large quantities of trapped pollen. If the desired research objective is to assess pollen quantities collected by colonies in an apiary, select representative colonies instead of optimizing the adult and larval populations for selection. All styles of pollen traps block the hive entrance and create a new entrance that differs spatially from the original entrance ${ }^{16}$. Pollen traps commonly fail to collect pollen when foragers are unable to reorient to the new entrance of the pollen trap upon installation. These foragers readily drift to neighboring hives, potentially cross-contaminating other pollen collection samples if they enter another hive with a pollen trap. Hence, foragers should be given at least $24 \mathrm{~h}$ to acclimate to the new entrance by keeping the trapping mechanism disengaged after installation. Selecting colonies with few or no additional hive entrances also reduces confusion when orienting to the new pollen trap entrance.

Additional hive entrances (e.g., holes and warped lids) should be sealed, but the risk of foragers drifting to neighboring hives will increase with these entrances present at the start of trap installation. Foragers will also readily drift into other hive entrances if a pollen trap is installed only on a single hive in a cluster of palletized hives. Foragers are less likely to drift if all the hives that are facing the same direction on the pallet have traps installed. Top-mount pollen traps may pose a higher risk of bee drift due to the substantial distance between the pollen trap entrance and the hive's original entrance. For this study, pollen traps were installed on multiple honey bee colonies in each experimental location to account for variation in the pollen quantity and taxa composition between each honey bee colony. Thus, pollen traps should be installed on multiple colonies to achieve robust pollen collections from the landscape because pollen collection can vary widely between colonies based on plant species type and total collected quantity ${ }^{12,13}$. Each pollen sample had a 7 -day collection period. In future studies, collecting pollen in two or three consecutive $72 \mathrm{~h}$ intervals will increase the accuracy of pollen forage estimation ${ }^{40}$.

As there is a high degree of temporal fluctuation in pollen collection, pollen estimation accuracy could be increased by repeating the pollen collection process in early, peak, and late blooming periods of the targeted cropping systems $24,27,39$. Pollen should be collected from multiple locations, albeit the same cropping system or landscape type, because of anticipated variation in quantity and plant species type between apiary locations $14,27,33,43$. Long-term pollen trapping can be detrimental to honey bee colonies. Potential impacts include reduced brood rearing, shortening of larval 
growth period, and cannibalism of eggs and young larvae in the hives ${ }^{19,44,45,46}$. Longer periods of pollen trapping, such as the entire growing season, can worsen the harmful effects on brood rearing in colonies. Pollen trapping can also cause a reduction in honey production and an increase in the moisture level of stored honey ${ }^{13}$. Rotating pollen traps between colonies in an apiary when continuously monitoring a landscape or cropping system could mitigate harm to colonies used for pollen trapping. Engaging pollen traps every other week will reduce detrimental impacts, particularly loss in honey production, if trapping pollen on the same colonies throughout a period of time ${ }^{13}$.

In addition, the pollen traps are preferably placed on strong colonies. Occasionally, the pollen traps may engage unintentionally. This could be avoided by locking the pollen trap mechanism when pollen trap collection is not desired. Pollen traps do not remove all corbicular pollen from honey bee foragers. Trapping efficiency depends on trap type, pollen pellet size, bee body size, the time of day, and weather conditions. Hence, corbicular pollen collection is not consistent when using pollen traps for different plant species and collection periods ${ }^{25,26}$. Smaller pollen pellets from plants such as Eucalyptus spp. and Tamarix spp. are less likely to be captured by pollen traps ${ }^{27}$. Notably, no highbush blueberry (Vaccinium corymbosum L.) pollen was found from the highbush blueberry collection sites in this study, which supports previous evidence that highbush blueberry pollen pellets are too small for pollen trap collection ${ }^{47}$. In contrast, pollen sourced from dandelion (Taraxacum officinale F.H. Wigg) was found in every cropping system in this study. Pollen pellets of some plant species can also be much larger than others, such as Taraxacum spp., and could possibly be overrepresented in the analysis of pollen collections from pollen traps $^{27}$. Capturing individual pollen foragers and manually removing their corbicular pollen will increase the accuracy of a pollen source assessment, but it is very time- and resourceintensive compared to using pollen traps (Table 1). Sorting pollen pellets into color groups is relatively straight forward, although it is time-consuming. Unless there is a specific research goal or objective, the quantity of pollen pellets should be limited to $10 \mathrm{~g}$ or less (for any given sample) for sorting into color groups. Sorting entire samples that contain greater quantities than this amount will drastically increase the time required to complete the analysis. It is, however, crucial that a pollen sample is very well-mixed before a subsample for color sorting is taken from it. Failing to mix the original sample may result in a subsample that is not representative of the whole, which should be avoided.

If the original sample container does not contain enough free space to allow for thorough mixing of pollen pellets, placing the whole sample in a large plastic bag or a small paper bag should suffice, even for large samples. Hard plastic, lidded containers will also work. Mixing the sample should be done gently, so that pollen pellets are not squashed or otherwise destroyed. Unintentional bias could subconsciously persuade one to scoop out "the pretty purple pellets", for example, when removing a subsample from the whole. Therefore, the sample's color composition should be obscured from view while scooping out a subsample. In this way, getting a subsample that is truly representative of the whole is more likely. However, this subsampling method could fail to select pollen pellets that are in low abundance in the sample. Therefore, if identifying every individual plant taxon represented in the sample is a research goal, collecting a subsample will not be appropriate; the whole sample must be analyzed. Hence, pellets should be sorted in a glass Petri dish. Once sorting is completed, appropriate pages of the Pantone color guide can be placed underneath the dish to 
make color-matching between the guide and the sorted pollen easier. An example of this is illustrated in Figure 5.

When trapping pollen from honey bee colonies placed in crops for pollination, no more than ten total color groups should be used: nine individual colors and one "miscellaneous" color group composed of the minority colors in the sample. Placing a reasonable limit on the maximum number of color groups that a sample can be divided into prevents the researcher from getting bogged down by endlessly separating pellets into ever-increasing numbers of extremely specific groups, which, when sorting is complete, may not individually contain sufficient quantities for acetolysis. If trapping from colonies that are likely foraging from a very diverse assortment of plant species, more color groups may be necessary, and the protocols should be optimized to reflect that requirement. The present study focused on the pollen samples collected from honey bee colonies pollinating crops, and multiple taxa were commonly found in a color group, similar to previous studies $29,30,31$.

Acetolysis dissolves the lipids, proteins, and organic debris from the surface of pollen grains, revealing the distinguishing characters of the exine, so that the grains can be stained and identified more easily. It is an old and common methodology used in many kinds of pollen research ${ }^{37}$. The general steps are standardized; they vary little from protocol to protocol. However, the specifics of centrifugation speeds and times, incubation temperature and duration, pollen-quantity-driven reagent volumes and even supernatant removal method (decanting vs pipetting) may need to be experimentally optimized according to research goals and, to some extent, the types of pollen likely to be encountered 48 . Indeed, acetolysis can remove important diagnostic characters of the pollen from some taxa such as Malvaceae and
Orchidaceae ${ }^{38}$. Therefore, not all pollen is amenable to standard methods of acetolysis. As stated above, these methods were optimized in this study for the purpose of identifying dominant plant taxon sources of pollen collected by crop-pollinating honey bees. Details to be considered if precise quantification of pollen grains is part of the study, have not been addressed in this paper.

The use of solvents and acids requires careful planning, proper personal protective equipment (PPE), and responsible waste disposal (Figure 6). It is critical that researchers determine the correct way to store reagents and dispose of waste before beginning any part of acetolysis. In this laboratory, butyl gloves are used during any part of the process that involves sulfuric acid and even glacial acetic acid as they have far better degradation and permeation ratings for both acids than nitrile gloves, while not compromising dexterity ${ }^{49}$. It would be prudent to consult the respective institution's safety guidelines for recommendations on appropriate gloves and other PPE ${ }^{49}$. Glacial acetic acid addition before the acetolysis step helps remove any residual moisture in the sample and prepares it for the important acetolysis reaction. The glacial acetic acid-sulfuric acid mixture in the acetolysis step may react violently with water, which is why it is important that all glassware and supplies be completely dry, and that all moisture is removed from the sample before acetolysis. The post-acetolysis addition of glacial acetic acid dilutes and neutralizes the acetolysis mixture.

Ethanol and glacial acetic acid, in particular, can dissolve the ink of microcentrifuge tube labels, if these reagents drip on the outside of the tube, even with solvent-resistant pens. Check the tube labels frequently throughout the process to be sure they are still legible. If logistically feasible, consider 
using LaserJet-printed labels as a safeguard against this possibility. The manner in which supernatants are decanted will influence whether reagents dribble down the outside of the microcentrifuge tubes. It is important to decant the supernatant with a confident, smooth hand, which comes with practice. Care should be taken to avoid loss of pollen samples from the centrifuge tube during decantation. Decanting too fast risks losing some or all of the pollen residue; decanting too slowly may result in the supernatant running down the tube. Although an incubation temperature of $100{ }^{\circ} \mathrm{C}$ is commonly recommended, pollen could easily become "overcooked" at that temperature in the quantities used in this study $(0.25 \mathrm{~g})$, particularly if incubated for slightly longer durations $^{29}$. In fact, even at $80{ }^{\circ} \mathrm{C}$, pollen grains can burst or otherwise be damaged if left in the acetolysis mixture too long. Incubation temperature and duration must be carefully determined to avoid destroying the pollen grains in the sample.

Staining pollen increases the definition and contrast of the exine features, making it easier to photograph and identify (Figure 7). Five drops (from a plastic transfer pipette) of $1 \%$ Safranin $\mathrm{O}$ effectively stained $0.25 \mathrm{~g}$ of pollen. However, different pollens stain differently. If pollen grains are stained too lightly or too heavily, identification may be difficult. When possible, the volume of the stain solution needed to appropriately stain the pollen species expected to be found in the study should be validated before beginning the processing of the experimental samples. Nonetheless, if one of the experimental samples is not properly stained, it can be corrected. To lighten a pollen sample that is stained too heavily, rinse the sample with water and then ethanol. If the pollen is not stained well enough to see distinguishing features, a few additional drops of stain can be added. The stain of these samples should be checked before adding glycerin. Likewise, some trial and error may be needed to determine the ideal volume of glycerin for the pollen residues. Fifteen drops of glycerin suitably protected the samples in this study from drying out, while also diluting the pollen residue to a concentration ideal for downstream identification via light microscopy. Other quantities of pollen residue may require more or less glycerin to prevent desiccation and facilitate mounting.

\section{Disclosures}

The authors have nothing to disclose.

\section{Acknowledgments}

We thank Dr. Gretchen Jones (USDA-ARS, APMRU, College Station, TX) for assisting with color sorting and acetolysis analysis. This research was supported by research funds provided to R.R.S. by the Oregon State Beekeepers Association.

\section{References}

1. Klein, A. M., Vaissière, B. E., Cane, J. H., SteffanDewenter, I., Cunningham, S. A., Kremen C., Tscharntke T. Importance of pollinators in changing landscapes for world crops. Proceedings of the Royal Society B: Biological Sciences. 274 (1608), 303-313 (2007).

2. vanEngelsdorp, D., Hayes, J., Underwood, R. M., Pettis J. S. A survey of honey bee colony losses in the United States, fall 2008 to spring 2009. Journal of Apicultural Research. 49 (1), 7-14 (2010).

3. vanEngelsdorp, D., Hayes, J., Underwood, R. M., Caron, D., Pettis, J. S. A survey of managed honey bee colony losses in the USA, fall 2009 to winter 2010. Journal of Apicultural Research. 50 (1), 1-10 (2011). 
4. vanEngelsdorp, D. et al. A national survey of managed honey bee 2010-11 winter colony losses in the USA: results from the Bee Informed Partnership. Journal of Apicultural Research. 51 (1), 115-124 (2012).

5. Spleen, A. M. et al. A national survey of managed honey bee 2011-12 winter colony losses in the United States: results from the Bee Informed Partnership. Journal of Apicultural Research. 52 (2), 44-53 (2013).

6. Steinhauer, N. A. et al. A national survey of managed honey bees 2012-2013 annual colony losses in the USA: results from the Bee Informed Partnership. Journal of Apicultural Research. 53 (1), 1-18 (2014).

7. Lee, K. V. et al. A national survey of managed honey bee 2013-2014 annual colony losses in the USA. Apidologie. 46 (3), 292-305 (2015).

8. Seitz, N. et al. A national survey of managed honey bee 2014-2015 annual colony losses in the USA. Journal of Apicultural Research. 54 (4), 1-12 (2016).

9. Kulhanek, K. et al. A national survey of managed honey bee 2015-2016 annual colony losses in the USA. Journal of Apicultural Research. 56 (4), 328-340 (2017).

10. Steinhauer, N. et al. Drivers of colony losses. Current Opinion in Insect Science. 26, 142-148 (2018).

11. Smart, M. D., Pettis, J. S., Euliss, N., Spivak, M. S. Land use in the Northern Great Plains region of the U.S. influences the survival and productivity of honey bee colonies. Agriculture, Ecosystems \& Environment. 230, 139-149 (2016).

12. Pettis, J. S., Lichtenberg, E. M., Andree, M., Stitzinger, J., Rose, R. Crop pollination exposes honey bees to pesticides which alters their susceptibility to the gut pathogen Nosema ceranae. PloS One. 8 (7), e70182 (2013).

13. Hoover, S. E., Ovinge, L. P. Pollen collection, honey production, and pollination services: managing honey bees in an agricultural setting. Journal of Economic Entomology. 111 (4), 1509-1516 (2018).

14. Topitzhofer, E., Lucas, H., Chakrabarti, P., Breece, C., Bryant, V., Sagili, R. R. Assessment of pollen diversity available to honey bees (Hymenoptera: Apidae) in major cropping systems during pollination in the western United States. Journal of Economic Entomology. 112 (5), 2040-2048 (2019).

15. Judd, H. J., Huntzinger, C., Ramirez, R., Strange, J. P. A 3D printed pollen trap for bumble bee (Bombus) hive entrances. Journal of Visualized Experiments. 161, e61500 (2020).

16. Delaplane, K. S., Dag, A., Danka, R. G., Freitas, B. M., Garibaldi, L. A., Goodwin, R. M., Hormaza, J. I. Standard methods for pollination research with Apis mellifera. Journal of Apicultural Research. 52 (4), 1-28 (2013).

17. Barker, R. J. The influence of food inside the hive on pollen collection by a honeybee colony. Journal of Apicultural Research. 10 (1), 23-26 (1971).

18. Levin, M. D., Loper, G. M. Factors affecting pollen trap efficiency. American Bee Journal. 124 (10), 721-723 (1984).

19. Webster, T. C., Thorp, R. W., Briggs, D., Skinner, J., Parisian, T. Effects of pollen traps on honey bee (Hymenoptera: Apidae) foraging and brood rearing during almond and prune pollination. Environmental Entomology. 14 (6), 683-686 (1985). 
20. Gemeda, T. K., Li, J., Luo, S., Yang, H., Jin, T., Huang, J., Wu, J., Nascimento, F. S. Pollen trapping and sugar syrup feeding of honey bee (Hymenoptera: Apidae) enhance pollen collection of less preferred flowers. PLoS One. 13 (9), e0203648 (2018).

21. Hellmich, R. L., Rothenbuhler, W. C. Relationship between different amounts of brood and the collection and use of pollen by the honey bee (Apis mellifera). Apidologie. 17 (1), 13-20 (1986).

22. Weidenmüller, A., Tautz, J. In-hive behavior of pollen foragers (Apis mellifera) in honey bee colonies under conditions of high and low pollen need. Ethology. 108 (3), 205-221 (2002).

23. Pernal, S. F., Currie, R. W. The influence of pollen quality on foraging behavior in honeybees (Apis mellifera L.). Behavioral Ecology and Sociobiology. 51 (1), 53-68 (2001).

24. Couvillon, M. J., et al. Honey bee foraging distance depends on month and forage type. Apidologie. 46, 61-70 (2015).

25. Percival, M. Pollen collection by Apis mellifera. New Phytologist. 46, 142-165 (1947).

26. Synge, A. D. Pollen collection by honey bees (Apis mellifera). Journal of Animal Ecology. 16, 122-138 (1947).

27. O'Neal, R. J., Waller, G. D. On the pollen harvest by the honey bee (Apis mellifera L.) near Tucson, Arizona (1976-1981). Desert Plants. 6, 81-109 (1984).

28. Eckert, C. D., Winston, M. L., Ydenberg, R. C. The relationship between population size, amount of brood, and individual foraging behaviour in the honey bee, Apis mellifera L. Oecologia. 97 (2), 248-255 (1994).
29. Free, J. B. The flower constancy of honey bees. Journal of Animal Ecology. 32 (1), 119-132 (1963).

30. van der Moezel, P. G., Delfs, J. C., Pate, J. S., Loneragan, W. A., Bell, D. T. Pollen selection by honeybees in shrublands of the Northern Sandplains of Western Australia. Journal of Apicultural Research. 26 (4), 224-232 (1987).

31. Hill, P. S., Wells, P. H., Wells, H. Spontaneous flower constancy and learning in honey bees as a function of color. Animal Behaviour. 54 (3), 615-627 (1997).

32. Barth, O., Munhoz, M., Luz, C. Botanical origin of Apis pollen loads using colour, weight and pollen morphology data. Acta Alimentaria. 38, 133-139 (2009).

33. Colwell, M. J., Williams, G. R., Evans, R. C., Shutler, D. Honey bee-collected pollen in agro-ecosystems reveals diet diversity, diet quality, and pesticide exposure. Ecology and Evolution. 7 (18), 7243-7253 (2017).

34. Stoner, K. A., Cowles, R. S., Nurse, A., Eitzer, B. D. Tracking pesticide residues to a plant genus using palynology in pollen trapped from honey bees (Hymenoptera: Apidae) at ornamental plant nurseries. Environmental Entomology. 48(2), 351.-362 (2019).

35. Almeida-Muradian, L., Pamplona, L. C., Coimbra, S. I., Barth, O. M. Chemical composition and botanical evaluation of dried bee pollen pellets. Journal of Food Composition and Analysis. 18 (1), 105-111. (2005).

36. Lau, P., Bryant, V., Rangel, J. Determining the minimum number of pollen grains needed for accurate honey bee (Apis mellifera) colony pollen pellet analysis. Palynology. 42(1), 36.-42 (2018).

37. Erdtman, G. Handbook of palynology: morphology, taxonomy, ecology: an introduction to the study of 
pollen grains and spores. Munksgaard, Copenhagen, DK (1969).

38. Jones, G. D. Pollen analyses for pollination research, acetolysis. Journal of Pollination Ecology. 13 (21), 203-217 (2014).

39. Richardson, R. T., Lin, C. H., Sponsler, D. B., Quijia, J. O., Goodell, K., Johnson, R. M. Application of ITS2 metabarcoding to determine the provenance of pollen collected by honey bees in an agroecosystem. Applied Plant Science. 3 (1), 1-6 (2015).

40. Dimou, M., Thrasyvoulou, A., Tsirakoglou, V. Efficient use of pollen traps to determine the pollen flora used by honey bees. Journal of Apicultural Research. 45 (1), 42-46 (2005).

41. Szczesna, T., Rybak-Chmielewska, H., Chmielewski, W. Effect of infestation of pollen loads with acarid mites on amino acid content and organoleptic characteristics of the product. Pszczelnicze Zeszyty Naukowe. 43 (1), 235-245 (1999).

42. Stoner, K. A., Eitzer, B. D. Using a hazard quotient to evaluate pesticide residues detected in pollen trapped from honey bees (Apis mellifera) in Connecticut. PLoS One. 8 (10), e77550 (2013).

43. Garbuzov, M., Couvillon, M. J., Schürch, R., Ratnieks, F. L. Honey bee dance decoding and pollen-load analysis show limited foraging on spring-flowering oilseed rape, a potential source of neonicotinoid contamination. Agriculture, Ecosystems \& Environment. 203, 62-68 (2015).

44. Moeller, F. E. Managing colonies for pollen production. pp. 232-239. Proceedings of 26th International Agricultural Congress. Adelaide, SA (1977).
45. Dustmann, J. H., Ohe, W. V. D. Einfluss von Kälteeinbrüchen auf die Frühjahresentwicklung von Bienenvölkern (Apis mellifera L.). Apidologie. 19 (3), 245-254 (1988).

46. Schmickl, T., Crailsheim. K. J. Cannibalism and early capping: strategy of honeybee colonies in times of experimental pollen shortages. Journal of Comparative Physiology A. 187 (7), 541-547 (2001).

47. Hodges, D. The pollen loads of the honeybee: a guide to their identification by colour and form. London Hill House, Chalfont St Peter, UK (1974).

48. Jones, G. D. Pollen extraction from insects. Palynology. 36 (1), 86-109 (2012).

49. Ansell. Chemical resistance guide. Permeation and degradation data. 8th Ed. Coshocton (OH): Ansell. (Form No CRG-GC-REV5-03). [Accessed 2020 September 13] https://ehs.unc.edu/files/2015/09/ Ansell_8thEditionChemicalResistanceGuide.pdf (2008). 